8 Metcalf MG, Donald RA. Fluctuating ovarian function in a perimenopausal woman. $N Z$ Med $\mathcal{F} 1979 ; 89: 45-7$.

9 Jacobs HS, Knuth UA, Hull MG, Franks S. Post-pill amenorrhoeacause or coincidence? $\mathrm{Br}$ Med f 1977;ii:940-2.

10 Pepperell RJ. Clinical investigation and assessment of amenorrhoea. Proceedings of 6th Asia Oceania Congress in Endocrinology. Singapore: Endocrine and Metabolic Society of Singapore, 1978:389-92.

11 Jones GS, De Moraes-Ruehsen M. A new syndrome of amenorrhoea in association with hyper-gonadotrophism and apparently normal ovarian follicular apparatus. Am f Obstet Gynecol 1969;104:597-600.

$12 \mathrm{Kim}$ MH. "Gonadotrophin-resistant ovaries" syndrome in association with secondary amenorrhoea. Am f Obstet Gynecol 1974;120:257-63.

${ }^{13}$ Dewhurst CJ, De Koos ED, Ferreria HE. The resistant ovary syndrome. Br F Obstet Gynaecol 1975;82:341-5.

14 Shapiro AG, Rubin A. Spontaneous pregnancy in association with hypergonadotrophic ovarian failure. Fertil Steril 1977;28:500-1.

15 Shangold MM, Turksoy RN, Bashford RA, Hammond CB. Pregnancy following "the insensitive ovary syndrome." Fertil Steril 1977;28 1179-81.

16 Szlachter BN, Nachtigall LE, Epstein J, Young BK, Weiss G. Premature menopause: a reversible entity ? Obstet Gynecol 1978;54:396-8.

17 Wright CS, Jacobs HS. Spontaneous pregnancy in a patient with hypergonadotrophic ovarian failure. Br $\mathcal{F}$ Obstet Gynaecol 1979;86:389-92.

18 Brown JB, MacLeod SC, MacNaughtan C, Smith MA, Smyth B. A rapid method for estimating oestrogens in urine using a semi-automatic extractor. F Endocrinol 1968;42:5-15.

19 Barrett SA, Brown JB. An evaluation of the method of Cox for the rapid analysis of pregnanediol in urine by gas liquid chromatography. $\mathcal{F}$ Endocrinol $1970 ; 47: 471-80$.
20 Pepperell RJ, Brown JB, Evans JH, Rennie GC, Burger HG. The investigation of ovarian function by measurement of urinary oestrogen and pregnanediol excretion. Br $\mathcal{F}$ Obstet Gynaecol 1975;82:321-2.

${ }^{21}$ Sutton C. The limitations of laparoscopic ovarian biopsy. Fournal of Obstetrics and Gynaecology of the British Commonwealth 1974;81:317-20.

${ }^{22}$ Logan Edwards R, Duignan NM, Rudd BT, Holder G, Butt WR. In : Diagnosis and treatment of ovarian neoplastic alterations. Amsterdam: Excerpta Medica, 1974:36. (Excerpta Medica International Congress Series No 364).

${ }^{23}$ Jones GS. Comment: the resistant ovary syndrome. Obstet Gynec Surv $1975 ; 30: 700$.

${ }^{24}$ Irvine WJ, Chan MM, Scarth L, et al. Immunological aspects of premature ovarian failure associated with idiopathic Addison's disease. Lancet 1968 ii :883-7.

${ }^{25}$ Coulam CR, Ryan RJ. Premature menopause: etiology. Am $\mathcal{f}$ Obstet Gynecol 1979;133:639-43.

${ }^{26}$ Thomas PR, Winstanley D, Peckham MD, Austin DE, Murray MA Jacobs HS. Reproductive and endocrine function in patients with Hodgkins disease: effects of oophorectomy and irradiation. $\mathrm{Br} \mathcal{F}$ Cancer $1976 ; 33$ :226-31.

${ }^{27}$ Sherman BM, Korenman SG. Hormonal characteristics of the human menstrual cycle throughout reproductive life. F Clin Invest 1975;55: 699-706.

${ }^{28}$ Reyes FI, Winter JS, Faiman C. Pituitary ovarian relationships preceding the menopause. Am f Obstet Gynecol 1977;129:557-64.

${ }^{29}$ Anonymous: Have I stopped ovulating yet? Lancet $1979 ; \mathrm{i}: 477-8$.

\title{
Management of female breast disease by Southampton general practitioners
}

\author{
S NICHOLS, W E WATERS, M J WHEELER
}

\section{Summary and conclusions}

One hundred and two Southampton general practitioners were interviewed about female breast disease. There was agreement about clinical management and the need to both teach and promote breast self-examination. The general practitioners, however, were divided as to whether any breast screening facilities were needed in Southampton. Records kept by the general practitioners of women seen with breast symptoms showed that one-quarter of all new episodes were referred to hospital at the first visit. That the general practitioners considered early diagnosis to be important was made evident from a number of the results. This attitude is encouraging in view of the evidence showing that longterm survival may be greater when delays are shorter.

\section{Introduction}

Few detailed studies in Britain have looked at general practitioners' views on the management of breast disease, although

This study was supported by a grant from the Department of Health and Social Security through the Wessex Regional Cancer Organisation.

\footnotetext{
Community Medicine, South Academic Block, Southampton General Hospital, Southampton SO9 4XY

S NICHOLS, BSC, CERTED, research assistant

W E WATERS, FFCM, DIH, professor

M J WHEELER, MSC, SRN, lecturer (present appointment: area nurse, child health, Kensington, Chelsea, and Westminster AHA(T))
}

this has been done with a sample of Australian doctors. ${ }^{1}$ In a study of the incidence and management of female breast disease in one practice in Birmingham five general practitioners were interviewed about their policies for managing patients with breast symptoms, but only a brief account of their views was reported. ${ }^{2}$ One of the aims of the present study, which constitutes one part of a broader research project evaluating health education in breast cancer, was to investigate general practitioners' views on managing female breast disease. A further aim was to determine the proportion of women with breast symptoms who were referred to hospital and the proportion dealt with by general practitioners alone.

\section{Methods}

All 112 NHS general practitioners and trainees practising in the City of Southampton were sent a letter explaining the purpose of the study and asking them to participate. This was followed within a few days by a telephone call to the surgery to arrange an interview. All interviews were conducted by SN between January and March 1980 The semi-structured questionnaire* contained items about breas disease including the clinical management, cancer survival rates and risk factors, breast self-examination and other screening methods, and health education.

At the end of the interview each doctor was asked to record, for four weeks, all women seen with breast symptoms. A booklet was provided for this purpose which, when completed, provided information about the age and presenting symptoms of each woman together with the action taken by the general practitioner.

*Copies of the questionnaire are available from $\mathrm{SN}$ 


\section{Results}

\section{SURVEY OF GENERAL PRACTITIONERS}

Altogether 102 general practitioners $\left(91^{\circ} \mathrm{o}\right)$, of whom 15 were women, participated in the survey. Only five declined, with the remainder either being unavailable or about to leave the practice.

Table I shows the general practitioners' level of optimism about the prognosis of women with breast cancer. Only 19 of the dortors gave estimates of between $80 \%$ and $90 \%$ which corresponded with the five-year survival rate for localised tumours of about $85 \%{ }^{3}$ The most frequently mentioned groups at increased risk of developing breast cancer were advancing age, followed closely by those with a family history and the nulliparous. The protective effect of having a pregnancy at a young age ${ }^{4}$ was hardly mentioned.

TABLE I-Optimism of Southampton general practitioners

Of 100 middle-aged women with early breast cancer, not found during mass screening and treated appropriately, how many would you expect to be alive five years after diagnosis?

None $\quad 1-24 \% \quad 25-49 \% \quad 50-74 \% \quad 75-79 \% \quad 100 \% \quad$ Don't

\begin{tabular}{llllllll}
$\begin{array}{l}\text { No of } \\
\text { general } \\
\text { practitioners }\end{array}$ & 1 & 5 & 13 & 52 & 26 & 1 & 4 \\
\hline
\end{tabular}

The general practitioners were asked whether a woman with early breast cancer should be told her diagnosis (table II). When asked under what circumstances, if any, they would not tell a woman with early breast cancer her diagnosis, 11 could not think of any such circumstances. Of those who mentioned at least one circumstance, 66 said if the woman's personality or psychological state was unsuitable, 28 if she did not want to know or did not ask, and 12 at the request of a relative.

TABLE II-Attitudes of Southampton general practitioners towards telling patients with breast cancer their diagnosis. Results are numbers of general practitioners

Do you think a woman with early breast cancer should be told her diagnosis ?

\begin{tabular}{lcccccc} 
& Always & Usually & $\begin{array}{c}\text { Usually } \\
\text { not }\end{array}$ & Never & Neutral* \\
\hline If she doesn't ask ? & 6 & 53 & 34 & 2 & 7 \\
If she asks directly? & 48 & 48 & 2 & 0 & 4 \\
\hline
\end{tabular}

*Those unable to give a clear preference.

Ninety-six of the 102 general practitioners thought that counselling was necessary for mastectomy patients. A mastectomy nurse was most preferred for this, followed by the general practitioner and the consultant. (The district did not employ a mastectomy nurse at this time.) It was also thought by some that a patient who had had a mastectomy herself could help; others said that the personal qualities of the counsellor were more important than their professional qualifications.

Table III shows the number of general practitioners who would examine women's breasts under certain given circumstances. Most

TABLE III-Number of Southampton general practitioners (102) who would examine women's breasts under given circumstances Under the following circumstances could you tell me if you would examine women's
breasts

\begin{tabular}{|c|c|c|c|c|c|}
\hline & Always & Usually & Sometimes & $\begin{array}{l}\text { Hardly } \\
\text { ever }\end{array}$ & Never \\
\hline \multirow{3}{*}{$\begin{array}{l}\text { Breast symptoms } \\
\text { Contraception } \\
\text { Pregnancy } \\
\text { Insurance medical } \\
\text { examination } \\
\text { Other general medical } \\
\text { examination }\end{array}$} & $\begin{array}{l}98 \\
36 \\
61\end{array}$ & $\begin{array}{r}3 \\
21 \\
15\end{array}$ & $\begin{array}{r}1 \\
27 \\
12\end{array}$ & $\begin{array}{r}0 \\
13 \\
5\end{array}$ & $\begin{array}{l}0 \\
5 \\
9\end{array}$ \\
\hline & 71 & 9 & 9 & 2 & 11 \\
\hline & 49 & 19 & 23 & 4 & 7 \\
\hline
\end{tabular}

took the opportunity for breast examination if consulted about breast symptoms and during pregnancy. Over half said they always or usually did so in association with contraceptive advice. Fifty-eight mentioned at least one circumstance, other than those specified in table III, when they would examine the breasts. Of these, 17 said they would do so if consulted about chest symptoms, 13 for conditions where the breast could be the primary site, 10 when carrying out a cervical smear, nine "at the patient's request," and eight at a postnatal examination.

In answer to the question: "If a woman has a breast lump, is a biopsy always necessary ?" 23 said yes, 76 no, and three did not know. When asked to expand on their replies, the circumstances most often mentioned by those against were when the diagnosis was either a cyst that could be aspirated (40) or fibroadenosis (23). The general practitioners were asked to name any circumstances under which breast symptoms should just be "observed." The most often mentioned were cyclical symptoms (35), pain or discomfort in the breast but no lump (22), and when the diagnosis was fibroadenosis (19).

Table IV shows the attitudes of the general practitioners to regular screening for women aged over 35 . While most were against regular breast radiography, there was a lack of consensus about the need for regular breast examination by a doctor. Nearly all were in favour of breast self-examination, however, more than half preferring that it should be practised on a monthly basis.

TABLE IV-Attitudes of Southampton general practitioners to regular screening. Results are numbers of general practitioners

There is some controversy about the advantages and disadvantages of regular There is some controversy about the advantages and disadvantages of regular
examination of the breast. For the following statements could you tell me if you are:

\begin{tabular}{lccccc}
\multicolumn{1}{c}{$\begin{array}{c}\text { Strongly } \\
\text { in favour }\end{array}$} & $\begin{array}{c}\text { In } \\
\text { favour }\end{array}$ & Neutral & Against & $\begin{array}{c}\text { Strongly } \\
\text { against }\end{array}$ \\
\hline $\begin{array}{c}\text { All women over 35 should: } \\
\begin{array}{c}\text { Have regular breast } \\
\text { palpation by a doctor }\end{array}\end{array}$ & 6 & 33 & 16 & 41 & 6 \\
$\begin{array}{c}\text { Have regular breast } \\
\text { radiography }\end{array}$ & 0 & 12 & 18 & 59 & 13 \\
$\begin{array}{c}\text { Regularly examine } \\
\text { their breasts }\end{array}$ & 55 & 43 & 4 & 0 & 0
\end{tabular}

How frequently should a woman examine her breasts ?

\begin{tabular}{ccccccc}
$\begin{array}{c}\text { Every bath } \\
\text { time }\end{array}$ & $\begin{array}{c}\text { Once a } \\
\text { week }\end{array}$ & $\begin{array}{c}\text { Once a } \\
\text { month }\end{array}$ & $\begin{array}{c}\text { Several } \\
\text { times a } \\
\text { year }\end{array}$ & $\begin{array}{c}\text { Once a } \\
\text { year }\end{array}$ & Other & $\begin{array}{c}\text { (Not in favour } \\
\text { of BSE) }\end{array}$ \\
\hline 3 & 17 & 58 & 18 & 0 & 2 & 4 \\
\hline
\end{tabular}

BSE $=$ Breast self-examination

Eighty-seven of the general practitioners had themselves taught breast self-examination during the previous 12 months, but the estimated number of women instructed ranged from 1 to 500, with a median of 20 (table V). Of those who had taught breast self-examination in the past year, most (74) showed women what to do but only one in nine also gave a pamphlet. Only six general practitioners had referred any women for instruction in this technique, but where this

TABLE V-Teaching of breast self-examination by Southampton general practitioners. Results are numbers of general practitioners

In the past year approximately how many women have you instructed in the pracIn the past year approximately
tice of breast self-examination?

\begin{tabular}{ccccccc} 
None & $1-24$ & $25-49$ & $50-74$ & $75-99$ & $>100$ & $\begin{array}{c}\text { Don't } \\
\text { know }\end{array}$ \\
\hline 15 & 35 & 14 & 8 & 5 & 18 & 7 \\
\hline
\end{tabular}

Who usually takes the initiative?
You The patient Other* Not applicable

\begin{tabular}{lccccc} 
You & The patient & Other* & \multicolumn{2}{c}{ Not applicable } & \\
\hline 67 & 13 & 7 & 15 & & \\
$\begin{array}{l}\text { Do you } \\
\text { Tell her }\end{array}$ & Show her & $\begin{array}{c}\text { Give a } \\
\text { pamphlet }\end{array}$ & $\begin{array}{c}\text { Tell and give } \\
\text { pamphlet }\end{array}$ & $\begin{array}{c}\text { Show and } \\
\text { give } \\
\text { pamphlet }\end{array}$ & $\begin{array}{c}\text { Not } \\
\text { applicable }\end{array}$ \\
\hline 12 & 66 & 1 & 0 & 8 & 15
\end{tabular}

*Six said in half the cases they took the initiative and in half it was the patient; one said it was a joint initiative. 
was the case the women had been referred to another health professional within the practice, such as a practice nurse. On the whole the general practitioners had no difficulties or restrictions in their ability to instruct women about breast self-examination, but time and other priorities were a constraint for 38 and the lack of a chaperon for 11 . Thirteen also mentioned other points, including the view that this was better undertaken by another woman.

There was disagreement about whether any breast screening facilities were needed in Southampton, with just over half (59) saying they were required (one did not know). Those in favour were asked which facilities should be provided. Thirty said mammography, 21 thermography, 48 clinical examination, and 49 the teaching of breast self-examination. Of those against breast screening facilities in Southampton (42), 29 agreed that there was insufficient evidence about a reduction in mortality and 27 that the economic costs would be too large. Twenty were concerned that there would be an increase in anxiety. Several other reasons were given, including the view that screening was best done as part of general practice.

In response to the question: "Do you think that general practitioners should play a part in breast cancer health education ?" 94 answered in the affirmative. Of these, 30 thought their contribution lay especially in teaching breast self-examination. Other points, each raised by one in five of the general practitioners, were that they have a part to play in all health education and that the doctor-patient relationship provides an ideal opportunity for health education.

The general practitioners were asked what messages they thought lumps in the breast with a further $50(21 \%)$ presenting with a lump or lumps together with other breast symptoms. Thus altogether 86 women (36\%) had a lump or lumps in the breast, of which $94 \%$ were discovered by the women themselves. Just over half the women (52\%) went to their general practitioner complaining of pain or discomfort only, with a few having one of these symptoms plus other non-specified symptoms. The remaining new episodes $(10 \%)$ were accounted for by women presenting with only symptoms other than lumps, pain, or discomfort. One-quarter of all new episodes were referred immediately to hospital, the remainder were either reassured or told to return to the surgery at a future date. Of those women presenting with a lump or lumps (86), 55\% were referred to hospital, while this was the case for only $9 \%$ of those without lumps.

\section{Discussion}

The high response rate achieved in the survey is an indication that general practitioners consider doctors' views on the management of breast patients to be an area worthy of investigation. This is supported by the duration of time given by many of them to the interview, far more than was necessary to complete the questionnaire. Further, 29 doctors, representing over half of the Southampton practices, attended a meeting to discuss the results.

TABLE VI-Presenting symptoms (new episodes only) and action taken by 93 Southampton general practitioners during four weeks

\begin{tabular}{|c|c|c|c|c|c|}
\hline \multirow{3}{*}{ Symptom/s } & \multicolumn{3}{|c|}{ Action taken by GPs } & & \\
\hline & \multirow{2}{*}{$\begin{array}{l}\text { Referred to } \\
\text { hospital* }^{*}\end{array}$} & \multirow{2}{*}{$\begin{array}{c}\text { Return } \\
\text { to } \\
\text { GP }\end{array}$} & \multirow{2}{*}{$\begin{array}{l}\text { Patient } \\
\text { reassured }\end{array}$} & \multicolumn{2}{|c|}{ Totals } \\
\hline & & & & \multicolumn{2}{|c|}{ No $(\%)$} \\
\hline $\begin{array}{l}\text { One lump only } \\
\text { More than one lump only } \\
\text { Pain or discomfort only } \\
\text { Other non-specified symptoms only } \\
\text { Lump and pain or discomfort } \\
\text { Lumps and pain or discomfort } \\
\text { One lump and other non-specified symptoms } \\
\text { More than one lump and other non-specified symptoms } \\
\text { Pain or discomfort and other non-specified symptoms }\end{array}$ & $\begin{array}{r}18 \\
3 \\
7 \\
5 \\
14 \\
11 \\
1 \\
0 \\
2\end{array}$ & $\begin{array}{r}7 \\
3 \\
49 \\
4 \\
11 \\
5 \\
0 \\
1 \\
3\end{array}$ & $\begin{array}{r}4 \\
1 \\
69 \\
15 \\
4 \\
3 \\
0 \\
0 \\
1\end{array}$ & $\begin{array}{r}29 \\
7 \\
125 \\
24 \\
29 \\
19 \\
1 \\
1 \\
6\end{array}$ & $\begin{array}{r}12 \cdot 0 \\
2 \cdot 9 \\
51 \cdot 9 \\
10 \cdot 0 \\
12 \cdot 0 \\
7 \cdot 9 \\
0 \cdot 4 \\
0 \cdot 4 \\
2 \cdot 5\end{array}$ \\
\hline Action taken totals & $\begin{array}{c}61 \\
25 \cdot 3 \%\end{array}$ & $\begin{array}{c}83 \\
34 \cdot 4 \%\end{array}$ & $\begin{array}{r}97 \\
40 \cdot 3 \%\end{array}$ & 241 & 100 \\
\hline
\end{tabular}

*Includes: Referred to hospital and return to general practitioner.

should be emphasised in public education about breast symptoms; the message most often (46) suggested was that breast symptoms should be reported to the doctor. Some of the general practitioners, however, only referred to reporting breast lumps, others to not only lumps but other breast symptoms as well, such as pain, discharge or bleeding from the nipple, skin changes, and inverted nipple. Still others did not specify any particular symptoms but just said that all breast symptoms should be reported. One-third of the doctors thought the message to the public should be or should include advice about not delaying once a breast symptom is found. Thirty-seven said that regular breast self-examination should be promoted. No other messages were suggested by more than one-quarter of the general practitioners.

\section{PROSPECTIVE STUDY OF CONSULTATIONS}

The records kept for four weeks by 93 general practitioners provided 331 consultations for analysis. These consultations were generated by 323 women, of whom $316(98 \%$ ) were seen only once during the period of the study. All seven of those seen more than once (six twice and one three times) had been told by their general practitioner, at the first consultation, to return to the surgery. The number of consultations recorded by the general practitioners over four weeks ranged from none to 11 , with a mean of 3.5 .

The 241 new episodes $(73 \%)$ were analysed in more detail. Their ages ranged from 16 to $84(75 \%$ were under 45 , with half of these aged from 25 to 34). Table VI shows the number of new episodes according to the presenting symptoms and the action taken by the general practitioners. Thirty-six women $(15 \%)$ presented with only a lump or
Few of the Southampton general practitioners were very pessimistic about the survival of middle-aged women with early breast cancer, with only $7 \%$ saying that a quarter or less would still be alive after five years. This attitude is matched by general practitioners in Sydney, Australia, where the corresponding figure was also $7 \% .{ }^{1}$ By contrast, in 1963 nearly $20 \%$ of a sample of 85 general practitioners were this pessimistic. ${ }^{5}$ Although the majority of the Southampton general practitioners were not too pessimistic, neither were they as optimistic as available statistics would justify.

Over the past 25 years there have been several studies concerned with hospital doctors' attitudes towards telling patients with cancer their diagnosis, and a review of these studies has shown a dramatic shift from generally not telling patients to generally telling them. ${ }^{6} \mathrm{~A}$ direct comparison cannot be made between the results of these studies and the present survey since the former differed in several ways. It is worth pointing out, however, that although nearly all Southampton general practitioners were in favour of telling the patient her diagnosis if she asked directly, there were a considerable number (35\%) who said they would usually not or never do so if she did not ask. In the Australian study of general practitioners $93 \%$ said they would always or usually tell a woman with early breast cancer her diagnosis, but no reference was made to whether or not the patient asked directly. ${ }^{1}$

A difference in approach between the Australian and Southampton general practitioners emerged on the question of 
the need for a biopsy. Only $23 \%$ of Southampton general practitioners, as compared with $59 \%$ of the Australian sample, thought that a biopsy was always necessary for a breast lump. Furthermore, the circumstance most often mentioned by Southampton general practitioners for which they considered a biopsy unnecessary was a breast cyst that could be aspirated, while this was mentioned by only $14 \%$ of the Australian doctors. The attitude of the Southampton doctors may, to some extent, have been gained through their correspondence with the professor of surgery and his colleagues to whom they refer most of their breast patients. The prospective study of consultations found that, of the new episodes, $36^{\circ} \%$ had a lump, which was very similar to that $(38 \%)$ found by Bywaters in his study of one practice in Birmingham.' Furthermore, of the new lumps, the percentage referred at the first consultation was $55 \%$ in the present study and $56 \%$ in Bywaters' study. In the present study, however, $52 \%$ of all the new episodes complained only of pain or discomfort in the breast while this was the case for only $28 \%$ of the women in the Birmingham study. It could be that the public's increased awareness about breast disease has caused more women with only pain or discomfort in the breasts to seek medical advice and reassurance that there is no serious disease.

The importance attributed by the general practitioners to early diagnosis was made clear from the results of the survey. One of the messages they thought should be emphasised in public education was the advantage of early presentation. This attitude is welcomed, particularly in view of the further evidence ${ }^{7}$ suggesting that in patients with breast cancer long-term survival is greater with a shorter delay between the appearance of symptoms and diagnosis. The general practitioners were much in favour of breast self-examination. If women practising this have shorter delay times ${ }^{3}$ then this attitude is well justified. The doctors also thought every available opportunity should be taken by them to check women's breasts and teach breast self-examination. Although in favour of breast self-examination, however, $15 \%$ had not taught any women in the past year (in the Australian study $17 \%$ said they did not teach it), such that altogether $36 \%$ had taught fewer than 12 women-that is, fewer than one a month. To support this we found that only $12 \%$ of women with breast symptoms attending the professorial surgical unit in Southampton said they had ever been taught by a general practitioner how to examine their breasts. It was heartening, however, to see that the majority of those general practitioners who were teaching breast self-examination were actually showing women what to do, rather than merely tell- ing them. Few were reinforcing their instruction with a pamphlet, but it emerged at the meeting that many of them were unaware that pamphlets could be obtained from the local health education office.

In contrast to the consensus of opinion about breast selfexamination, a substantial number $(41 \%)$ were against introducing any breast-screening facilities locally. Interestingly, this view emerged when an assessment of the most recent data from the Health Insurance Plan of New York shows a benefit (in terms of mortality) from periodic screening, at least in women aged $50-64 .^{9}$

Finally, it was encouraging to hear a positive attitude towards their involvement in breast cancer health education. Rather than thinking in terms of simply displaying posters in their waiting rooms, many suggested a more active role by teaching breast self-examination. Many considered that the doctor-patient relationship provided an ideal opportunity for health education. As one general practitioner put it: "Every consultation is an opportunity for health education."

We thank the general practitioners for their co-operation and $\mathrm{Mr}$ Andrew Hayes (Wessex Regional Cancer Organisation) for his support.

\section{References}

${ }^{1}$ Hill DJ, Todd P, Magarey CJ, et al. A survey of doctors' attitudes to breast cancer and self-detection methods. Aust Fam Physician 1976; $\mathbf{5}: 815-20$.

${ }^{2}$ Bywaters JL. The incidence and management of female breast disease in a general practice. $\mathcal{F} R$ Coll Gen Pract 1977;27:353-7.

3 National Cancer Institute. Cancer patient survival. Report No 5. Bethesda, Md: National Cancer Institute, 1976. (DHEW publication No (NIH) 77-992.)

${ }^{4}$ MacMahon B, Cole P, Lin TM, et al. Age at first birth and breast cancer risk. Bull WHO $1970 ; 43: 209-21$.

5 Easson EC. The role of the doctor in public education. In: Health education theory and practice in cancer control. Geneva: UICC, 1974;10:14-20.

${ }^{6}$ Novak DH, Plumer R, Smith RL, Ochitill H, Morrow GR, Bennett JM. Changes in physicians' attitudes toward telling the cancer patient. $\mathcal{F} A M A$ $1979 ; 241$ :897-900.

${ }^{7}$ Elwood JM, Moorhead WP. Delay in diagnosis and long-term survival in breast cancer. Br Med $\mathcal{F} 1980 ; 280: 1291-4$.

8 Phillips AJ, Brennan ME. The reaction of Canadian women to the PAP test and breast self-examination. Can Fam Physician 1976;22:71-4.

${ }^{9}$ Shapiro S. Evidence on screening for breast cancer from a randomised trial. Cancer $1977 ; 39: 2772-82$.

(Accepted 2 October 1980)
ONE HUNDRED YEARS AGO For a week, Mr Gladstone's ultimo, not feeling well and wishing to be quiet, he dined with Lord Frederick Cavendish, and he had no sooner sat down than he had a rigor. He was compelled to retire from the table, and having been made warm and comfortable, he felt much better, and later was about to proceed to the House of Commons, when happily it was found that it had been counted out. He recovered, and on Saturday morning felt pretty well; but at 12 o'clock, he had a second rigor. Mrs Gladstone then, feeling alarmed, consulted Dr Andrew Clark, his usual medical attendant, who shortly visited the Premier, and found him coming downstairs to go to a meeting of the Cabinet. His temperature was $103^{\circ}$, and he was at once sent to bed. In the evening the temperature rose to $103 \cdot 5^{\circ}$. Mr Gladstone passed a restless night, and, under no other medicinal influence than that of a little citrate of ammonia, he was drenched with exhausting sweats. On Sunday morning, the temperature had fallen, and the patient expressed himself as feeling much better. This improvement continued until late in the afternoon, when suddenly the temperature again rose to $103^{\circ}$, the pulse and respirations being accelerated; and the base of the left lung, which at first had been somewhat dull and crepitating, exhibited signs of increased congestion. There was again a restless night, with profuse sweating. On Monday morning, the temperature was $101.5^{\circ}$, and the local symptoms were unaltered. In the evening, the temperature again rose to $103^{\circ}$, and there were again profuse perspirations. At this stage, the exhibition of two teaspoonfuls of brandy on two separate occasions produced an immediate and unfavourable effect, complained of by the patient: the sweats were suddenly checked, the skin dried, and the sense of malaise heightened. The night was similar to the two preceding ones, except that movement in bed produced cough On Tuesday morning, about 9 o'clock, the temperature had fallen to $100^{\circ}$, and the respirations and pulse had become less frequent. Within an hour, however, the temperature rose to $102^{\circ}$, and was followed by profuse sweating. About midday, the temperature, pulse, and respirations fell to the average of health, and continued normal during the rest of the day and the succeeding night. On Wednesday morning, $\mathrm{Mr}$ Gladstone was again seen by Sir W Jenner (who had visited him on Monday) and Dr Andrew Clark, when it was found that the signs of congestion of the lung had disappeared, that the fever had subsided, and that beyond weakness, the natural result of the attack through which the patient had passed, he was free from evidence of disease. This condition has been happily maintained up to the present time (Thursday evening). Mr Gladstone, of course, feels much weakness, but is making most satisfactory progress; and, as he seems to be quite free from all organic disease, there is every reason to expect that his restoration will be complete. (British Medical fournal, 1880.) 